\title{
IDENTIFIKASI SEBARAN VEGETASI BERBASIS DATA MODIS MENGGUNAKAN METODE NORMALIZED DIFFERENCE VEGETATION INDEX (NDVI)
}

\author{
Adamul Istikanah $^{1, \mathrm{a})}$, Cecep E. Rustana ${ }^{1, \mathrm{~b})}$, Trismidianto ${ }^{2, \mathrm{c})}$, Risyanto ${ }^{2, \mathrm{~d})}$ \\ ${ }^{1}$ Program Studi Fisika, Fakultas Matematika dan Ilmu Pengetahuan Alam, Universitas Negeri Jakarta. \\ ${ }^{2}$ Pusat Sains dan Teknologi Atmosfer, Lembaga Penerbangan dan Antariksa Nasional \\ Email: a)adamulistikanah02@gmail.com, ${ }^{\text {b) }}$ crustana@unj.ac.id, ${ }^{\mathrm{c})}$ trismidianto@lapan.go.id, \\ d)risyanto@lapan.go.id
}

\begin{abstract}
Abstrak
Peningkatan jumlah penduduk dan pembangunan di Pulau Jawa berimplikasi pada ketersediaan lahan hijau yang semakin menurun. Teknologi penginderaan jauh dapat dimanfaatkan secara langsung untuk pengawasan luas lahan atau adanya konversi alih fungsi lahan di Pulau Jawa. Penelitian ini dilakukan untuk menganalisa sebaran vegetasi dan perubahan luasan sebaran di Pulau Jawa menggunakan data MODIS. Metode yang digunakan adalah Normalized Difference Vegetation Index (NDVI). Hasil dari penelitian menunjukan bahwa perbandingan data spasial tahun 2018 dan 2019 melalui identifikasi sebaran kelas kerapatan vegetasi di Pulau Jawa menggunakan metode NDVI, adanya penyusutan kelas vegetasi di Pulau Jawa tahun 2018 hingga 2019 yang tertinggi adalah kelas vegetasi kehijauan sedang (KS) meliputi daerah sawah dan kebun sebesar $9.622 \mathrm{~km} 2$ atau 6,877\%, sedangkan kenaikkan luas lahan vegetasi terbesar adalah kelas vegetasi kehijauan sangat rendah (KSR) meliputi daerah lahan kosong dan pemukiman sebesar $8.579 \mathrm{~km} 2$ atau $6,131 \%$.
\end{abstract}

Kata-kata kunci: NDVI, MODIS, Indeks Vegetasi, Penyusutan Vegetasi

\begin{abstract}
The increase in population and development in Java has implications for land degradation. Remote sensing technology can be used to oversight of land or the conversion of land use functions in Java. This research was to analyze the distribution of vegetation and degradation in the distribution area in Java using MODIS data. The method that will be applied is the Normalized Difference Vegetation Index (NDVI). The results indicated that based on the comparison of spatial data in 2018 to 2019 through the identification of the distribution of vegetation density classes in Java using the NDVI method, the highest degradation of vegetation classes in Java from 2018 to 2019 was medium green vegetation (KS) covering rice fields and gardens about $9,622 \mathrm{~km}^{2}$ or $6,877 \%$, while the largest increase in vegetation land area was very low greening vegetation classes (KSR) covering vacant land areas and settlement abaout $8,579 \mathrm{~km}^{2}$ or $6,131 \%$.
\end{abstract}

Keywords: NDVI, MODIS, Vegetation Index, Vegetation Degradatio. 


\section{PENDAHULUAN}

Dinamika pembangunan ditandai dengan transformasi perubahan struktur ekonomi dan demografi. Efek demografi atau ilmu kependudukan adalah ilmu yang mempelajari statistik pada distribusi, komposisi penduduk dan komponen perubahannya[1]. Badan Pusat Statistik (2018), jumlah laju pertumbuhan penduduk (Population Growth Rate) terbesar (The Large Population) berada di Pulau Jawa sebesar 148.171 orang dan terbesar pada Provinsi Jawa Barat sebesar 48.037 orang[2]. Jumlah perubahan distribusi penduduk di Pulau Jawa, khususnya mengenai kepadatan dan penyebaran penduduk menjadi salah satu efek terkait konversi alih fungsi lahan vegetasi di Pulau Jawa.

Selain adanya perubahan struktur ekonomi dan efek demografi, pertanian menjadi salah satu hal yang perlu diperhatikan dalam pengawasan luas lahan pertanian. Pertanian merupakan komoditi utama di Negara Indonesia, khususnya di Pulau Jawa [3]. Potensi kondisi tanah yang subur di Indonesia, membuat beberapa daerah menjadi kawasan sentra produksi pangan (agropolitan)[4]. Berdasarkan Kementerian Pertanian (pada Databoks Kata Data, 2017) ada 10 Provinsi di Indonesia yang tergolong menjadi kawasan sentra produksi pangan (agropolitan). Pulau Jawa masih menjadi sentra padi nasional dengan produksi mencapai 40,37 juta ton atau hampir separuh produksi nasional [5].

Pulau Jawa memiliki intensitas pemanfaatan lahan lebih tinggi dibandingkan dengan pulau lain karena perluasan lahan pertanian sudah sangat terbatas [6]. Sementara tuntutan kebutuhan lahan untuk pengembangan sektor industri, jasa, dan perumahan semakin meningkat dan kemungkinan tidak dapat dihindari sejalan dengan pertumbuhan ekonomi wilayah [6].

Melihat fenomena tersebut, maka penelitian ini dilakukan untuk melihat perubahan luas sebaran vegetasi di Pulau Jawa pada periode waktu 2018-2019. Dengan adanya perubahan pada periode tersebut, maka hasil penelitian ini dapat menjadi salah satu bahan evaluasi pembangunan, proyeksi sebaran penduduk, mempertahankan luas lahan panen dan pemanfaatan lahan terbuka hijau di Pulau Jawa.

Pemanfaatan teknologi penginderaan jauh digunakan untuk mendeteksi sebaran vegetasi, kerapatan vegetasi, dan luas vegetasi pada suatu wilayah berbasis data MODIS (Moderate-resolution Imaging Spectroradiometer). Metode NDVI (Normalized Difference Vegetation Index) merupakan sebuah transformasi matematis dalam penajaman citra spektral untuk membedakan warna, luas serta batasan area[4].

\section{MODIS (Moderate-resolution Imaging Spectroradiometer)}

Produk MODIS yang digunakan memiliki resolusi $1000 \mathrm{~m}$ atau $1 \mathrm{~km} 2$ memiliki saluran reflektan dan radian [7]. Tinjauan permukaan yang menyimpan hasil citra melindungi ozon, partikel awan, suhu atmosfer, dan suhu permukaan [7]. Sensor MODIS memiliki 36 kanal spektrum (spectral band) atau grup berdasarakan panjang gelombang [8]. Produk MODIS direkam oleh sensor kembar pada satelit Aqua dan Terra [8].

Pada data satelit Aqua / Terra senson MODIS terdapat data level $1 \mathrm{~b}$ yaitu data satelit yang sudah berformat komputer-friendly [9]. Data yang sudah berformat level 1b dapat diimplementasikan ke metode produk geofisika. Data level $1 \mathrm{~b}$ dan level 2 untuk satelit data MODIS mempunyai format file HDF (Hierarchical Data Format) [9].

\section{Metode NDVI (Normalized Vegetation Index)}

Indeks vegetasi merupakan nilai kehijauan yang dapat dijadikan sebagai satu parameter untuk menganalisa keadaan vegetasi dari suatu wilayah [4]. Indeks vegetasi digunakan sebagai metode transformasi citra berbasis data spektral dan memiliki banyak manfaat [10]. Indeks vegetasi diperoleh dengan menggunakan suatu metode dengan membentuk kombinasi beberapa saluran (band) [10].

Nilai indeks vegetasi diperoleh dari perbedaan antara penyerapan maksimun saluran merah oleh klorofil, serta refleksi maksimum saluran inframerah dekat oleh jaringan mesofil[11]. 


$$
\mathrm{NDVI}=\frac{\mathrm{NIR}-\mathrm{RED}}{\mathrm{NIR}+\mathrm{RED}}
$$

Keterangan :

NIR : Saluran inframerah (saluran 16 MODIS)

Red : Saluran merah (saluran 13 MODIS)

NDVI mempunyai nilai yang hanya berkisar antara -1 (non vegetasi) hingga 1 (vegetasi). Setelah NDVI diperoleh, langkah selanjutnya adalah membuat skala warna (color map) tingkat vegetasi agar diperoleh informasi lebih lanjut.

TABEL 1. Rentang Klasifikasi NDVI [12]

\begin{tabular}{|c|c|}
\hline Rentang Klasifikasi NDVI & Kerapatan \\
\hline$-1<N D V I<-0,03$ & Lahan tidak bervegetasi \\
$-0,03<N D V I<0,15$ & Kehijauan sangat rendah \\
$0,15<N D V I<0,25$ & Kehijauan rendah \\
$0,25<N D V I<0,35$ & Kehijauan sedang \\
$0,35<N D V I<1$ & Kehijauan tinggi \\
\hline
\end{tabular}

\section{METODOLOGI}

Metode yang digunakan adalah melakukan intrepertasi data satelit level $1 \mathrm{~b}$ dan level 2 Aqua / Terra dengan sensor MODIS (Moderate-resolution Imaging Spectroradiometer) tahun 2018 - 2019 daerah Pulau Jawa terletak antara $107,82^{\circ}-113,64^{\circ}$ (BT) dan $6,28^{\circ}-8,6^{\circ}$ (LS). Dalam sensor MODIS, untuk menghitung sebaran vegetasi dan penyusutan lahan menggunakan metode NDVI (Normalized Difference Vegetation Index). Pengolahan kuantitatif kelas vegetasi dan kekeringan serta hasil data spasial menggunakan software Python 3.8.

\section{HASIL DAN PEMBAHASAN}

Pada pengolahan metode NDVI, klasifikasi daerah penelitian menjadi 5 (lima) kelas yaitu : Lahan tidak bervegetasi (LTB), kehijauan sangat rendah (KSR), kehijauan rendah (KR), kehijauan sedang (KS), dan kehijauan tinggi (KT). Gambar 1 adalah hasil spasial dalam bentuk citra yang menampilkan perbedaan warna klasifikasi vegetasi NDVI di Pulau Jawa antara tahun 2018 dan 2019.

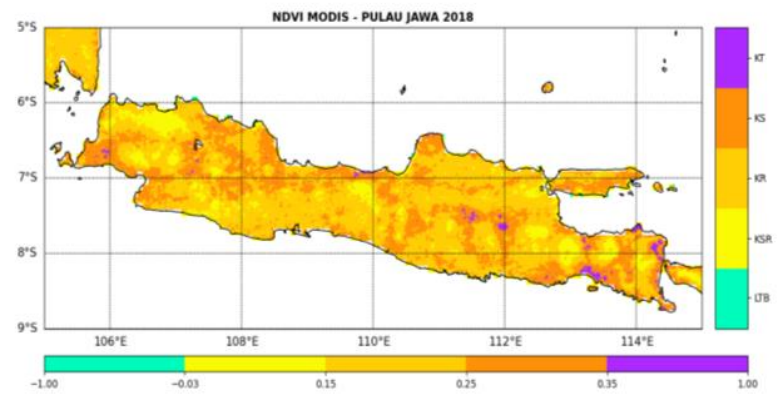

(a)

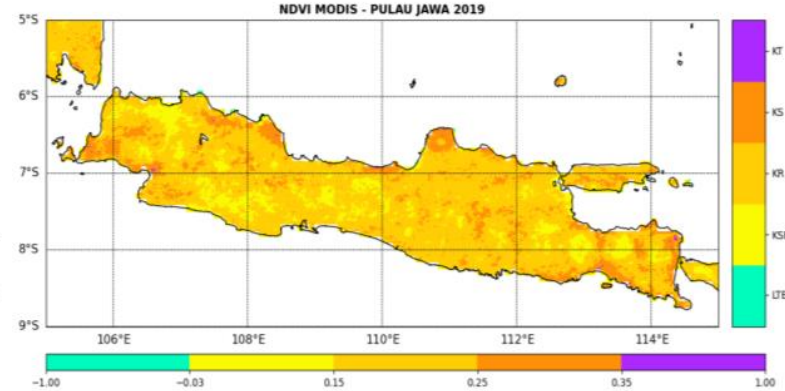

(b)

GAMBAR 1. Hasil Citra Spasial Klasifikasi Kelas Vegetasi NDVI Pulau Jawa (a) Tahun 2018, (b) Tahun 2019

Setelah mendapatkan nilai rentang NDVI, dilakukan perhitungan luas dan presentase dari masingmasing kelas. Kemudian didapatkan total perubahan luas lahan pada masing-masing kelas vegetasi dan non vegetasi. 
TABEL 2. Luas Lahan Pulau Jawa Berdasarkan Kelas Vegetasi NDVI 2018 - 2019

\begin{tabular}{|c|c|c|c|c|c|c|c|}
\hline \multirow[t]{2}{*}{ Klasifikasi NDVI } & \multirow[t]{2}{*}{ Kode } & \multicolumn{2}{|c|}{2018} & \multicolumn{2}{|c|}{2019} & \multicolumn{2}{|c|}{$\begin{array}{c}\text { Total Perubahan Luas } \\
\text { Lahan } \\
2018-2019 \\
\end{array}$} \\
\hline & & $\begin{array}{c}\text { Presentase } \\
(\%)\end{array}$ & $\begin{array}{c}\text { Luas } \\
\left(\mathbf{K m}^{2}\right) \\
\end{array}$ & $\begin{array}{c}\text { Presentase } \\
(\%)\end{array}$ & $\begin{array}{c}\text { Luas } \\
\left(\mathbf{K m}^{2}\right) \\
\end{array}$ & $\begin{array}{c}\text { Presentase } \\
(\%)\end{array}$ & $\operatorname{Luas}\left(\mathbf{K m}^{2}\right)$ \\
\hline $\begin{array}{l}\text { Lahan tidak } \\
\text { bervegetasi }\end{array}$ & LTB & 2,091 & 2926 & 1,083 & 1515 & $-1,008$ & -1411 \\
\hline $\begin{array}{l}\text { Kehijauan sangat } \\
\text { rendah }\end{array}$ & KSR & 52,759 & 73821 & 58,891 & 82400 & 6,131 & 8579 \\
\hline $\begin{array}{l}\text { Kehijauan } \\
\text { rendah }\end{array}$ & $\mathbf{K R}$ & 33,579 & 46985 & 35,657 & 49891 & 2,077 & 2906 \\
\hline $\begin{array}{l}\text { Kehijauan } \\
\text { sedang }\end{array}$ & $\mathbf{K S}$ & 11,212 & 15688 & 4,335 & 6066 & $-6,877$ & -9622 \\
\hline Kehijauan tinggi & KT & 0,357 & 500 & 0,034 & 48 & $-0,323$ & -452 \\
\hline Jumlah & & 100 & 139920 & 100 & 139920 & $\mathbf{0}$ & $\mathbf{0}$ \\
\hline
\end{tabular}

Kelas lahan tidak bervegetasi (LTB) di Pulau Jawa pada tahun 2018 memiliki luas $2.926 \mathrm{~km} 2$ $(2,091 \%)$, sedangkan tahun 2019 sebesar $1.515 \mathrm{~km} 2$ (1,083\%). Adanya perubahan penurunan luas lahan tidak bervegetasi seluas $1.411 \mathrm{~km} 2(-1,008 \%)$, dapat diartikan kelas lahan tidak bervegetasi dapat mencakup nilai awan, batuan, badan air, maupun lautan [13].

Kelas vegetasi kehijauan sangat rendah (KSR) di Pulau Jawa pada tahun 2018 memiliki luas $73.821 \mathrm{~km} 2(52,729 \%)$, sedangkan tahun 2019 sebesar $82.400 \mathrm{~km} 2(58,891 \%)$. Adanya perubahan perluasan lahan kelas kehijauan sangat rendah sebesar $8.579 \mathrm{~km} 2(6,131 \%)$, dapat diartikan kelas lahan kehijauan sangat rendah meliputi lahan kosong dan pemukiman [13]. Nilai kelas vegetasi kehijauan sangat rendah (KSR) adalah kelas vegetasi dengan luasan terbesar dibandingkan kelas lainnya. Dapat diartikana bahwa adanya konversi pengalihan fungsi lahan hijau akibat kepadatan penduduk. Hal ini sejalan dengan hasil Badan Pusat Statistik Nasional bahwa Pulau Jawa menjadi pulau terpadat di Indonesia, dengan terbukti adanya kenaikkan luas lahan kosong dan pemukiman seluas $8.579 \mathrm{~km} 2$ atau sebesar $6,131 \%$.

Kelas lahan kehijauan rendah (KR) di Pulau Jawa pada tahun 2018 memiliki luas $46.985 \mathrm{~km} 2$ (33,579\%), sedangkan tahun 2019 sebesar $49.891 \mathrm{~km} 2$ (35,657\%). Adanya kenaikkan perluasan lahan kelas kehijauan rendah sebesar $2.906 \mathrm{~km} 2(2,077 \%)$, dapat diartikan kelas lahan kehijauan rendah adalah kelas klasifikasi meliputi daerah pertanian atau persawahan [13]. Hal ini karena hampir setengah luas Pulau Jawa adalah wilayah persawahan dan penduduk Pulau Jawa bermatapencaharian di sektor pertanian. Hasil publikasi BPS 2018 dan 2019 juga menyatakan luas lahan pertanian / luas lahan persawahan hingga produksi padi nasional hampir lima puluh persen berasal dari Pulau Jawa.

Kelas vegetasi kehijauan sedang (KS) di Pulau Jawa pada tahun 2018 memiliki luas $15.688 \mathrm{~km} 2$ $(11,212 \%)$, sedangkan tahun 2019 sebesar $6.066 \mathrm{~km} 2$ (4,335\%). Adanya penurunan lahan kelas kehijauan sedang sebesar $9.622 \mathrm{~km} 2(6,877 \%)$, dapat diartikan kelas vegetasi kehijauan sedang adalah vegetasi meliputi sawah dan kebun [13]. Tetapi vegetasi pada kelas ini jarang sekali ditemui pada daerah penelitian karena perbedaan masa tanam padi saat pengambilan data satelit / citra dengan waktu validasi yang berjarak 9 bulan.

Kelas vegetasi kehijauan tinggi (KT) adalah tanaman yang berwarna hijau dan memiliki kerapatan vegetasi yang tinggi, seperti tegalan dan hutan [13]. Menurut hasil pengolahan spasial NDVI (gambar 1a) tahun 2018, kelas vegetasi ini tersebar di Provinsi Jawa Timur. Kelas vegetasi kehijauan tinggi (KT) di Pulau Jawa pada tahun 2018 memiliki luas $500 \mathrm{~km} 2$ (0,357\%), sedangkan tahun 2019 sebesar $48 \mathrm{~km} 2(0,034 \%)$. Adanya penurunan luas tegalan dan hutan sebesar $452 \mathrm{~km} 2(0,323 \%)$, spasial NDVI gambar 1b tahun 2019 tidak terlihat adanya luasan vegetasi kehijauan tinggi. 


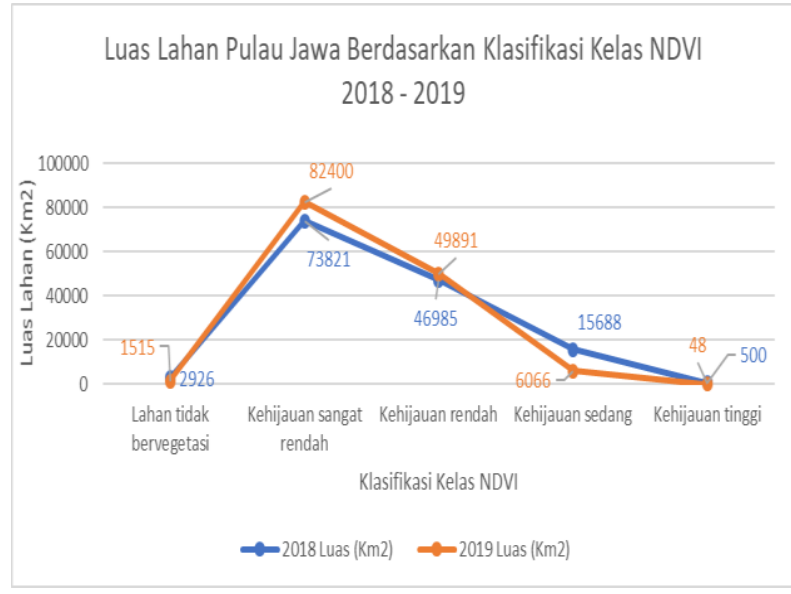

GAMBAR 2. Grafik Luas Lahan Pulau Jawa Berdasarkan Klasifikasi Kelas NDVI 2018 - 2019
Presentase Penurunan Luas Lahan 2018 - 2019

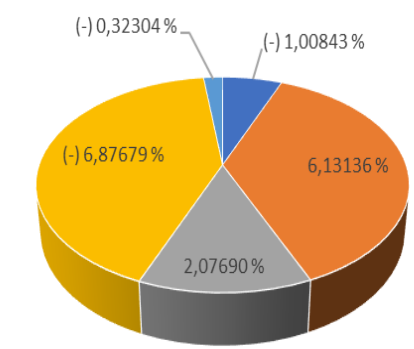

- Lahan tidak bervegetasi LTB - Kehijauan sangat rendah KSR

- Kehijauan rendah KR = Kehijauan sedang KS

- Kehijauan tinggi KT

GAMBAR 3. Presentase Penurunan Luas Lahan Vegetasi Metode NDVI 2018 - 2019

Dalam grafik luas lahan dan presentase perubahan kelas vegetasi di Pulau Jawa tahun 2018 hingga 2019 terbesar penurunannya adalah kelas vegetasi kehijauan sedang (KS) dengan penyusutam luas lahan daerah sawah dan kebun sebesar $9.622 \mathrm{~km} 2$, pada tahun 2018 adalah $15.688 \mathrm{~km} 2$ menjadi $6.066 \mathrm{~km} 2$ di tahun 2019. Sedangkan kelas vegetasi yang memiliki kenaikkan luas daerah terbesar adalah kelas vegetasi kehijauan sangat rendah (KSR) meliputi daerah lahan kosong dan pemukiman sebesar $8.579 \mathrm{~km} 2$ yaitu tahun 2018 seluas $73.821 \mathrm{~km} 2$ menjadi $82.400 \mathrm{~km} 2$.

Perubahan luas pada kelas vegetasi membuktikan adanya pengalihan fungsi lahan hijau / wilayah pertanian menjadi wilayah pemukiman akibat adanya kepadatan penduduk (demografi) atau perubahan mekanisme sektor ekonomi dari pertanian menjadi daerah perkotaan.

\section{SIMPULAN}

Hasil dari penelitian ini menyimpulkan bahwa dari analisis sebaran vegetasi dengan metode NDVI, presentase penyusutan kelas vegetasi di Pulau Jawa tahun 2018 hingga 2019 tertinggi adalah kelas vegetasi kehijauan sedang (KS) meliputi daerah sawah dan kebun sebesar $9.622 \mathrm{~km} 2$ atau $6,877 \%$, sedangkan kenaikkan luas lahan vegetasi terbesar adalah kelas vegetasi kehijauan sangat rendah (KSR) meliputi daerah lahan kosong dan pemukiman sebesar $8.579 \mathrm{~km} 2$ atau $6,131 \%$.

Hasil penelitian membuktikan adanya pengalihan fungsi lahan hijau / wilayah pertanian menjadi wilayah pemukiman akibat adanya kepadatan penduduk (demografi) atau perubahan mekanisme sektor ekonomi dari pertanian menjadi daerah perkotaan.

\section{UCAPAN TERIMAKASIH}

Terimakasih kepada Pusat Sains dan Teknologi Atmosfer (PSTA), Lembaga Penerbangan dan Antariksa Nasional (LAPAN) yang telah menyediakan data MODIS.

\section{REFERENSI}

[1] Sakamoto et al., "17th Demography of Social Stratification," Handbooks of Sociology and Social Research, p. 457, 2019.

[2] Statistik Indonesia, "Badan Pusat Statistik," Jakarta: CV. Dharma Putra Indonesia, p.75, 2018.

[3] Mahendra, Yoga, "Rancang Bangun Sistem Pendukung Keputusan Pengelompokkan Kabupaten / Kota di Pulau Jawa Berdasarkan Komoditas Pertanian Berbasis Sistem Informasi Geografis," Repository of Universitas Airlangga, 2016. 
[4] M. W. Trinugroho \& Mawardi, "Pemantauan Area Genangan Air Pada Rawa Lebak Menggunakan Teknologi Penginderaan Jauh," Preface Geomatika, Indonesia, vol. 23, no. 2, pp. 49-56, 2017.

[5] Databoks Kata Data, "10 Provinsi Dengan Produksi Padi Terbesar 2017 Riset Kementrian Pertanian,” Retrieved from KataData.net, 2017.

[6] K. S. Swastika Dewa et al., "Analisis Kebijakan Peningkatan Produksi Padi Melalui Efesiensi Pemanfaatan Lahan Sawah di Indonesia," Retrieved from repository.pertanian.go.id, vol. 5, no. 1, 2007.

[7] Li, Shuangshuang et al., "NDVI-Based Analysis on The Influence of Climate Change and Human Activities on Vegetation Restoration in The Shaanxi-Gansu-Ningxia Region," Central China, Retrived from ReasearchGate, 2015.

[8] Albarakath, Reyadh, Laksmi Venkantaraman, "Comparison of Normalized Difference Vegetation Index Derived from Landsat, MODIS, and AVHRR for the Mesopotamian Marshes 2002 and 2018," Journal of Remote Sensing, Columbia, p. 2, 2019.

[9] Alonso et al., "Coupling high-resolution field monitoring and MODIS for reconstructing wetland historical hydroperiod at a high temporal frequency," Remote Sensing of Environment, Belgium, vol. 247, p. 7, 2020.

[10] W. A. Puruitaningrum, "Penentuan Kandungan Aerosol di Atmosfer Menggunakan Data Terra/Aqua MODIS," Universitas Indonesia, 2010.

[11] Andini et al., "Analisis Sebaran Vegetasi dengan Citra Satelit Sentinel Menggunakan Metode NDVI dan Segmentasi," Jurnal Geodesi Undip, Semarang, vol. 7, no. 1, pp. 18-19, 2018.

[12] M. Nilasari, B. Sasmito \& A. Sukmono, "Aplikasi Penginderaan Jauh Untuk Memetakan Kekeringan Lahan Pertanian Dengan Metode Thermal Vegetation Index (Studi Kasus: Kabupaten Kudus, Jawa Tengah),” Jurnal Geodesi Universitas Diponegoro, 2017.

[13] Wilson et al., "Assement of Climate Impact on Vegetation Dynamics Over East Africa from 1982 to 2015," Retrieved from Nature Reasearch. 